\title{
Publisher Correction: The unmapped chemical complexity of our diet
}

Albert-László Barabási @, Giulia Menichetti@ and Joseph Loscalzo

Correction to: Nature Food https://doi.org/10.1038/s43016-019-0005-1, published online 9 December 2019.

In the version of this Perspective originally published, in the top-left structure in Fig. 1, 'CH' should have read 'OH'. In the second paragraph of the section 'Health implications', the text 'Taken together, there are at least six distinct biochemicals in our diet that affect TMAO production' should have read 'Taken together, there are at least six distinct biochemicals in our diet involved in the TMAO pathway'. In Fig. 2, the labels at the top of the yellow and red boxes mistakenly read 'Individual foodome'; they should have read 'Individual genome' and 'Individual diseases', respectively. In the green box in Fig. 2, in the top compound, the bonds between $\mathrm{N}$ and $\mathrm{C}$ were double but should have been single in two instances; and an $\mathrm{H}$ single bond with $\mathrm{C}$ was missing from both the second- and third-from-top compounds. All of these errors have now been corrected.

Published online: 21 January 2020

https://doi.org/10.1038/s43016-020-0030-0

(c) Springer Nature Limited 2019 